\title{
Ters sarkacın uyarlamalı kazançlı bağımsız yüzeyli kayan kip yöntemi ile denetimi
}

\author{
Fuat KILIÇ*, Sabri BİCAKCI, Hüseyin GÜNEŞ \\ Balıkesir Üniversitesi Mühendislik Fakültesi, Mekatronik Mühendisliği Bölümü, \\ Çăglş kampüsü, Balıkesir. \\ Geliş Tarihi (Received Date): 02.08.2019 \\ Kabul Tarihi (Accepted Date): 18.09.2019
}

\section{Özet}

Bu çalışmada gerçek bir ters sarkaç sistemi için yeni bir uyarlamalı kazançlı, bă̆ımsız yüzeyli kayan kip denetim tekniği (UKKKD) önerilmektedir. Böylece modellenemeyen ve üst sinır değerleri belirli olmayan bozucu etkilere karşı dayanıkl bir denetim yapısı elde edilmektedir. Önerilen denetim yöntemi ile dayanıklılık özelliği en küçük kazanç değerlerinde dahi korunmakta ve böylece kayan kip denetimin temel problemi olan çatırtı etkisi de azaltılmaktadır. Çalışmada, ters sarkaç ve denetim sisteminin MATLAB/SIMULINK benzetim ile uygulama grafikleri karşılaştırmalı olarak verilmiş ve denetimin olumlu etkisi doğrulanmuştır.

Anahtar kelimeler: Ters sarkaç, kayan kip, uyarlamalı kazanç, dayanıklı denetim.

\section{Adaptive gain decoupled sliding mode control of inverted pendulum}

\begin{abstract}
In this study, a new adaptive gain, decoupled surface sliding mode control technique is proposed for a real inverted pendulum system. Thus a robust control structure against unmodeled and uncertain upper limit valued disturbances is developed. With the proposed control method, the robustness property is preserved even at the smallest gain values and thus the chattering effect, which is the main problem of the sliding mode control, is reduced. In this study, MATLAB / SIMULINK simulations and experimental
\end{abstract}

\footnotetext{
*Fuat KILIÇ, fuatkilic@balikesir.edu.tr, http://orcid.org/0000-0003-2502-3789

Sabri BİCAKCI, sbicakci@bakikesir.edu.tr, http://orcid.org/0000-0002-2334-8515

Hüseyin GÜNEŞ, hgunes@balikesir.edu.tr, http://orcid.org/0000-0001-6927-5123
} 
results of the inverted pendulum control system are compared and the positive effect of the proposed control method is confirmed.

Keywords:Inverted pendulum, sliding mode, adaptive gain, robust control.

\section{Giriş}

Ters sarkaç sistemi, bir hareketli araba üzerinde yer alan açık çevrim kararsız yüksek dereceli doğrusal olmayan, eksik eyleyicili bir sistemdir. Ters sarkaç sisteminin modellenmesi ve denetimi, kontrol sistemleri mühendisliği alanında kalite ölçüt testi olarak kullanılmasının yanında, askeri endüstri, uzay bilimleri, insansı robotlar, personel taşıyıcı sistemler, kendi kendini dengeleyen araçlar ve medikal sistemler gibi uygulamalarda da kullanılmaktadır [1-4]. Sarkaç çubuğunun dikey konumda tutulması ve arabanın sistem girişine uygulanan referansı takip etmesi amaçlanan iki önemli kontrol problemidir.

Literatürde, sarkacı dikeyde tutmak ve arabanın sistem girişine uygulanan referansı takip etmesi için bang-bang denetim, bulanık mantık, PID, dayanıklı denetim, öngörülü denetim, yapay sinir ağları (YSA), doğrusal karesel regülatör (DKR), doğrusal Gaussian regülatör (DGR), pasivite tabanlı denetim ve geri adımlı denetim gibi çeşitli yöntemler kullanılmaktadır [4-8]. PID denetim en çok kullanılan yöntemlerden biri olmakla birlikte arzu edilen denetim cevapları elde edilememiştir. Kayan kesirli çift PID nin kazanç optimizasyonu için parçacık sürü optimizasyonu (PSO), genetik algoritmalar (GA), karınca kolonisi (KK) optimizasyonu gibi teknikler kullanılmaktadır [5,6]. Ancak sistem parametrelerin sıcaklık vb. etkiler altında değişimi ve belirsiz iç ve dış bozucu etkilerin olduğu durumda PID denetim yöntemi arzu edilen denetim cevaplarını sağlayamamaktadır. PSO, GA ve YSA tabanlı denetim teknikleri yoğun matematiksel işlemlere ihtiyaç duyulması ve mikrodenetleyici hafızasında oldukça büyük yer işgal etmesinden dolayı uygulama zorluklarına sahiptirler. Sistemin doğrusal olmayan yapısı, doğrusal denetim yapısına sahip olan DKR ve DGR yöntemleriyle istenilen denetim başarımını elde etmeyi zorlaştırır. Geri adımlı denetimin de benzer şekilde yoğun matematiksel denklemler gerektirmesi, anılan yöntemlerin ters sarkaç sistemi denetiminde dezavantajlar meydana getirmektedir.

Kayan kipli denetim (KKD), dayanıklı değişken yapılı denetim olarak sistem belirsizliklerine ve bozucu etkilere karşı çok az etkilenmektedir [9]. Kayan kip denetimin üstün olan diğer yönleri ise hılı cevaba sahip olması ve kayan kipte belirsizlikleri kompanze etmesidir [10]. Ancak, elektromekanik sistemlerde modellenemeyen dinamiklerin bulunduğu durumlarda; kayan kip denetimin en büyük dezavantajı olan çatırtı etkisinin bastırılması ve denetimin dayanıklılık özelliğinin korunması istenen iki ana hedeftir [11]. KKD, elektromekanik sistemlerde süreksiz fonksiyon diğer bir ifade ile işaret fonksiyonu kullanılarak gerçekleştirilir. Bu durumda çatırtı etkisi ortaya çıkmaktadır. Yüksek frekanslı anahtarlama fonksiyonu, mekatronik sistemlere doğrudan uygulandığında sistemin denetim başarımını azaltabildiği gibi kararlılığ 1 da kötüleştirebilir [12].

Literatürde çatırtı problemi, hala çözülmesi gereken bir problem olarak önemini korumaktadır. Çatırtı azaltma yöntemleri arasında doyma fonksiyonu kullanımı, sigmoid fonksiyonu kullanımı, bozucu etki gözetleyicisi, uyarlamalı kazanç yöntemi en 
çok kullanılan yöntemlerdendir [13-18]. Bu yöntemler arasında çatırtının genliğini en çok etkileyebilecek parametre anahtarlama fonksiyonunun çarpanıdır. Bu çarpanın genliğinin değişmesi doğrudan çatırtının azaltılmasına neden olmaktadır. Bu çalışmada, sarkacın dikey konumda kalmasını ve arabanın yatay hareketinde referans değeri takip etmesini sağlamak için iki farklı kayan kip yüzey ve uyarlamalı kayan kip denetim kazancını hata bileşenlerine göre tasarlayarak, çatırtı etkisi bastırılmış dayanıklı denetim cevabı elde edilmiştir.

$\mathrm{Bu}$ çalışmanın birinci bölümünde literatürde yer alan çalışmalar ve içerikleri sunulmuştur. Bundan sonraki ikinci bölümde ters sarkaç sisteminin modellenmesi ve eşitlikleri, üçüncü bölümde uyarlamalı kazançlı kayan kip denetim ve kararlılık analizi ve son bölümde benzetim ve uygulama sonuçları yer almaktadır.

\section{Ters sarkaç sistemi ve matematiksel modeli}

Şekil 1'de ters sarkaç sisteminin şematik bir gösterimi verilmiştir. $\mathrm{X}$ ekseni boyunca araba sınırlı bir harekete sahiptir. Z ekseni etrafında serbest dönen ve kararsız olan sarkacı Y eksenine paralel dik konumda tutabilmek için araba bir motor yardımıyla hareket ettirilir. Arabanın izlenmesi gereken yatay yörünge üzerinde merkez noktadan uzaklığı $x$ ile, sarkaç çubuğunun dikey konumda Y eksenine göre yaptığı açı ise $\theta$ ile ifade edilmektedir.

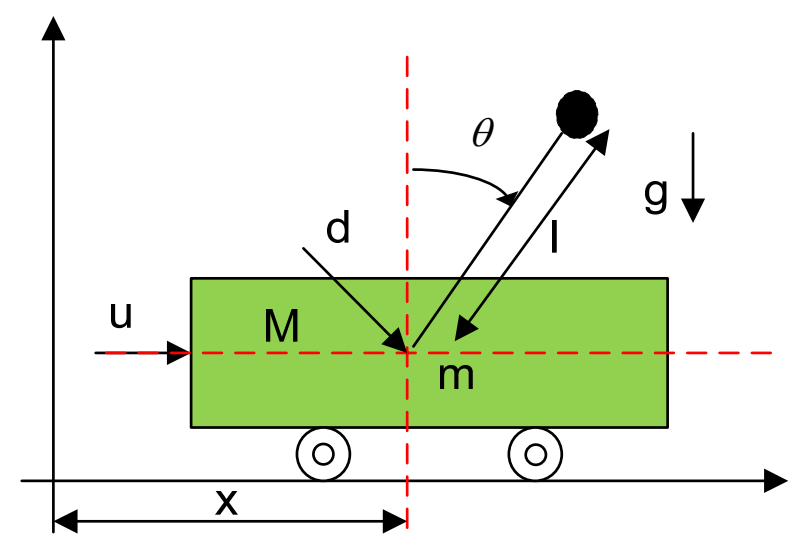

Şekil 1. Ters sarkaç sistemi.

Ters sarkaç sisteminin dinamik modeli Lagrange yönteminden yararlanılarak elde edilebilmektedir. Bunun için sistemin kinetik enerjisi $K_{e}$,

$$
K_{e}=\frac{1}{2} M \dot{x}^{2}+\frac{1}{2} m\left[\dot{x}^{2}+2 l \dot{x} \cos \theta+\dot{x}^{2} l^{2}\right]
$$

eşitliği ile ifade edilir. Burada; $M$ araba kütlesi $(\mathrm{kg}), m$ sarkaç kütlesi $(\mathrm{kg}), l$ sarkaç çubuğunun uzunluğu (m), $\theta$ sarkaç çubuğunun dikey eksenle yaptığı açı (rad), $g$ yerçekimi ivmesini simgelemektedir. Potansiyel enerji,

$P_{e}=-m g l \cos \theta$ 
şeklinde tanımlanmaktadır. Lagrange eşitliği,

$L=K_{e}-P_{e}$

şeklinde verilmektedir. Lagrange eşitliği kullanılarak ters sarkaç sisteminin doğrusal olmayan matematiksel modeli,

$$
\begin{aligned}
& (m+M) \ddot{x}+b \dot{x}+m l \ddot{\theta} \cos (\theta)-m l \dot{\theta}^{2} \sin (\theta)=u \\
& m l \ddot{x} \cos (\theta)+\left(I+m l^{2}\right) \ddot{\theta}-m g l \sin (\theta)+d \dot{\theta}=0
\end{aligned}
$$

eşitlikleri ile ifade edilebilir. $d$ sarkaç sönümleme katsayısı (Nms/rad), I sarkacın atalet momentidir $\left(\mathrm{kgm}^{2}\right)$. Durum uzay modelini oluşturmak için ters sarkaç sisteminde kullanilan parametreler,

$$
X=\left(x_{1} x_{2} x_{3} x_{4}\right)^{t}=(x \theta \dot{x} \dot{\theta})^{t}
$$

eşitliği ile ifade edilebilir. Buna göre ters sarkaç sisteminin durum uzay modeli [19]

$$
\left\{\begin{array}{l}
\dot{x}_{1}=x_{3} \\
\dot{x}_{3}=f_{1}(x)+\Delta f_{1}(x)+\left(g_{1}(x)+\Delta g_{1}(x)\right) u \\
\dot{x}_{2}=x_{4} \\
\dot{x}_{4}=f_{2}(X)+\Delta f_{2}(X)+\left(g_{2}(x)+g_{2}(x)\right) \Delta u
\end{array}\right.
$$

denklem takımı halinde yazılabilir. Burada; $f_{1}, g_{1}, f_{2}, g_{2}$ doğrusal olmayan fonksiyonlar ve $u$ denetim girişidir. Ters sarkaç sisteminin fiziksel parametreleri Tablo 1 de verilmiştir.

Tablo 1. Ters sarkacın fiziksel parametreleri

\begin{tabular}{lll}
\hline \hline Sembol & \multicolumn{1}{c}{ Büyüklük } & \multicolumn{1}{c}{ Değer } \\
\hline$m$ & Sarkacın kütlesi & $2.09838 \mathrm{~kg}$ \\
$l$ & Ağırlık merkezinin uzunluğu & $0.25535 \mathrm{~m}$ \\
$I$ & Sarkacın atalet momenti & $0.05052 \mathrm{~kg} \cdot \mathrm{m}^{2}$ \\
$g$ & Yer çekimi ivmesi & $9.81 \mathrm{~m} / \mathrm{s}^{2}$ \\
$M$ & Arabanın kütlesi & $1.70411 \mathrm{~kg}$ \\
$r$ & Kasnak yarıçapı & $0.012415 \mathrm{~m}$ \\
$N$ & Dişli oranı & 8 \\
$\eta$ & DC motorun verimi & 0.90 \\
$K_{t}$ & Tork sabiti & $0.0385 \mathrm{~N} . \mathrm{m} / \mathrm{A}$ \\
$K_{b}$ & Ters elektro motor kuvvet katsavısı & $0.0385 \mathrm{~V} . \mathrm{s} / \mathrm{rad}$ \\
$R_{a}$ & Armatür direnci & $0.103 \mathrm{ohm}$ \\
$J_{m}$ & Motorun atalet momenti & $6.03 \mathrm{e}-5 \mathrm{~kg} \cdot \mathrm{m}^{2}$ \\
$F_{f p}$ & Sarkacın viskoz sürtünme sabiti & 0 \\
$F_{f c}$ & Arabanın viskoz sürtünme sabiti & $72.49 \mathrm{~N} . \mathrm{s} / \mathrm{m}$ \\
\hline \hline
\end{tabular}

İlgili değerler ve doğrusal olmayan ters sarkaç denklemlerinden,

$$
f_{1}(x)=0.6061 \cdot x_{2}-219.7351 \cdot x_{3}
$$




$$
\begin{aligned}
& g_{1}(x)=8.7394 \\
& f_{2}(x)=29.7913 \cdot x_{2}-628.4698 \cdot x_{3} \\
& g_{2}(x)=24.9957
\end{aligned}
$$

eşitlikleri kolaylıkla çıkartılır.

\section{Uyarlamalı kazançlı arık yüzeyli kayan kip denetim}

Kayan kipli denetim (KKD), hassasiyet, denetim sisteminin çalışmasına olumsuz etkileri olabilecek tüm bozucu etkilere karşı dayanıklılık, kolay denetim ayarı ve uygulanma özelliklerini hedefleyen doğrusal olmayan bir denetim tekniğidir. KKD' de amaç durum değişkenlerini durum uzayının içerisinde özel olarak seçilen bir alana sürmektir. $\mathrm{Bu}$ alanın diğer ismi kayma yüzeyidir. Durum değişkenlerini kayma yüzeyine ulaştırmak ikinci aşamada da kayma yüzeyinin etrafinda küçük zikzaklar yaptırarak hedefe ulaşmak tasarımın bir parçasıdır. Tasarımın diğer amacı ise denetim amaçlarını sağlayacak uygun bir denetim kanunu seçmektir [21].

Ters sarkacın bağımsız kayma yüzeyli denetimindeki temel amaç, yatay eksende arabanın denetimi, dikey eksende ise sarkacın dengede tutulmasının sağlanmasıdır. Bu durum iki farklı kayma yüzeyi oluşturulabileceği anlamına gelir. Bu yüzeyler temelde ters sarkacın doğrusal olmayan denklem sistemine bakıldığında dolaylı olarak birbirleri ile ilgilidir. Buna göre, kayma yüzeyleri $s_{1}$ ve $s_{2}$ durum değişkenlerine bağlı olarak tasarlanabilir. Kayma yüzeyleri ise parametrelere bağlı olarak tekrar düzenlenirse,

$$
\begin{aligned}
& s_{1}=c_{1}\left(e_{1}-z\right)+\dot{e}_{1} \\
& e_{1}=\theta-\theta_{r e f} \\
& s_{2}=c_{2} e_{2}+\dot{e}_{2} \\
& e_{2}=x-x_{r e f}
\end{aligned}
$$

eşitlikleri elde edilir. $z$ ara değişkeni ile kayma yüzeyleri arasındaki denetim ilişkisi sağlanır. $c_{1}, c_{2}, \beta$ ve $\phi$ sabit katsayılardır.

$$
z=\beta \operatorname{sign}\left(\frac{s_{2}}{\phi}\right) \cong \beta \operatorname{sat}\left(\frac{s_{2}}{\phi}\right)
$$

Süreksiz işaret fonksiyonu (İngilizce kısaltma sign) diğer bir ifade ile anahtarlama fonksiyonu elektriksel sistemler için uygun olsa da ters sarkaç gibi mekanik sistemlerde titreşim ve istenmeyen başka durumlara yol açabilir. Çatırdama olarak da adlandırılan istenmeyen etkileri azaltmak için seçilen yöntemlerden bir tanesi süreksiz işaret fonksiyonu yerine doyum fonksiyonu kullanmaktır. Bundan sonraki aşama denetim kanununu seçmektir.

$$
u=u_{e d}+u_{a n}
$$


Denetim kanunu, iki bileşenden meydana gelmektedir. Bunlar Eş. 16-18'de verilen $u_{e d}$ eşdeğer denetim ve $u_{a n}$ anahtarlama terimi bileşenleridir. Eşdeğer denetim bileşeni kayma yüzeyinin türevinin sıfıra eşitlenmesinden elde edilmektedir.

$u_{e d}=\frac{-c_{1} x_{2}-f_{1}(x)}{g_{1}(x)}$

$u_{a n}=\frac{-\lambda s a t\left(s_{1}\right)}{g_{1}(x)}$

Herhangi bir uyarlama tasarımı yapılmadan kullanılan kayan kipli denetim kanunları parametre değişimi ve belirsizliklere karşı duyarsızdır [22]. Kayan kipin uygulanmasındaki temel sorun, süreksiz işaret fonksiyonunun yani anahtarlama fonksiyonunun genliği ile orantılı olan çatırdama ve denetim tepkisi frekansının yüksek oluşudur. Çatırdama etkisini azaltmak için kullanılan yöntemlerden biri sınır katmanı uygulamasıdır. Bir diğer yaklaşım ise yüksek dereceli kayan kip denetim uygulamasıdır. Ancak bu teknikte belirsizlikleri oluşturan etkilerin sınırlarının bilinmesi gereklidir. Bu sebeple amaç belirsizlik sınırlarının bilinmesini gerektirmeyen buna ilave olarak ani olarak ortaya çıkabilecek bozucu etkilere karşı dayanıklı bir denetim yapısı oluşturmaktır [23]. Özet olarak amaç, her iki problemi en az düzeye indirmek için kayan kipin var olduğu durumda süreksiz fonksiyon genliğini kararlılık sınırları içinde en az düzeye indirmektir. Bunun için de en iyi yol anahtarlama fonksiyonunun genliğini değiştiren kazancı en düşük seviyeye uyarlamalı olarak indirmektir. Uyarlamalı denetimin temel amacı belirsizlik durumlarına karşı sabit kazançla aynı dinamik cevabı verebilecek denetim sistemi tasarlamaktır. Bu amaçla elde edilecek uyarlamalı kazanç dinamiklerinin mevcut denetim sistemi dinamiklerine en az düzeyde etki edecek şeklide tasarlanması gereklidir.

Dinamik uyarlamalı kazanç kanunun yukarıda bahsedilen şartlar çerçevesinde kayan kip denetim tabanlı oluşturulabilmesi gerekir. Bu nedenle temel kayan kip denetim kanunu olan,

$u=-\lambda \operatorname{sign}(s(x, t))$

eşitliğinden hareketle $s \neq 0$ olduğu durumda, uyarlamalı kazanç $\dot{\lambda}=\lambda_{1}|s(x, t)|$ ile verilebilir. $\lambda_{1}>0$ iken uyarlamalı kazanç değişse de $s=0$ olana kadar sürekli artış gösterir. Kayan kip durumu devam ettiğinde çatırtının azaltılması için istenen amaçlar sağlanamaz. Bunun için istenen amaçlara uygun hem ani bozucu etkilere karşı dinamik değişen kazanç olup hem de kayan kipin devam ettiği durumda çatırtı etkisini en aza indirecek kazanç eşitliği,

$\dot{\lambda}=\left\{\begin{array}{lr}\lambda_{1}|s(x, t)| \operatorname{sign}(|s(x, t)|-\mu) & \text { ĕger } \lambda>\varepsilon \\ \varepsilon & \text { eğer } \lambda<\varepsilon\end{array}\right.$

olarak yazılabilir. Burada $\mu$ kayan kip evresine ulaşıldığında dinamik kazanç değerine azaltıcı etki yapan sabit katsayıdır. Bağımsız yüzeyler için uyarlamalı kazanç eşitliği hatanın her var olduğu durumda artmakta veya azalmaktadır. Hatanın artması ile kazanç değeri büyümekte ve kalıcı durum hatasının azaltılması sağlanmaktadır. Hatanın azaldığ́ durumda ise kazanç genliği azalmakta bu durumda anahtarlama genliği de 
azalmakta ve çatırdama etkisi de azalmaktadır. Ters sarkaç sisteminin denetiminde dıştan gelebilecek ani bozucu etkilere karşı da kazanç dinamik olarak hızlıca değişmekte ve bu bozucu etkilere karşı da dayanıklı bir denetim sağlanmaktadır. Kayan kip evresinin devam ettiği sürece kayma yüzeyinin etrafındaki ufak salınımlar devam ettiği için kazanç sabit kalmaktadır. Bozucu etkilerin var olmadığı durumda, kayan kip evresinin devam edebilmesi için en küçük değerine inen kazanç sıfirdan büyük sınır değer, $\varepsilon$ değerinde tutulur.

\subsection{Kararlılık analizi}

Uyarlamalı kazanç ve sistem denetim girişinin Lyapunov tabanlı kararlılık analizinin yapılması için aday fonksiyon,

$V(s)=\frac{1}{2} s^{2}+\frac{1}{2}\left(\lambda-\lambda^{*}\right)^{2}$

şeklinde seçilebilir. Seçilen Lyapunov aday fonksiyonu karesel bir fonksiyon ve türevi negatif olmalıdır. $\lambda^{*}, \lambda$ uyarlamalı kazancının en üst sınır değerleridir. Sistemde meydana gelebilecek belirsizlikler sınırlı olduğundan kazanç değeri de sınırlıdır. $V(s)$ aday fonksiyonunun türevi alınırsa,

$$
\begin{aligned}
\dot{V} & =s \dot{s}+\dot{\lambda}\left(\lambda-\lambda^{*}\right) \\
& =s \dot{s}+\bar{\lambda}|s(x, t)| \operatorname{sign}(|s(x, t)|-\mu)\left(\lambda-\lambda^{*}\right)
\end{aligned}
$$

$\operatorname{sign}(|s(x, t)|-\mu)$ terimi sürekli pozitif değerler alır. Bu sebeple kaynak giriş terimi,

$u=-\eta_{1} \operatorname{sign}(s, t)$

formunda yazılabilir. $\eta_{2}=-\bar{\lambda}|s(x, t)|$ alınırsa,

$\dot{V} \leq-\eta_{1}|s|-\eta_{2}\left(\lambda-\lambda^{*}\right)$

eşitliği elde edilir. Elde edilen eşitlik normu alınarak,

$$
\begin{aligned}
\dot{V} & \leq-\eta\left(\frac{s^{2}}{2}+\frac{\left|\lambda-\lambda^{*}\right|^{2}}{2}\right)^{\frac{1}{2}} \\
& \leq-\eta V^{\frac{1}{2}}
\end{aligned}
$$

eşitsizliği ile sınırlı zaman yakınsaması sağlanır. Burada $\eta_{1}$ ve $\eta_{2}$ sabit sayılardır.

$$
\eta=\min \left(\sqrt{2} \eta_{1}, \sqrt{2} \eta_{2}\right)
$$

\section{Benzetim ve deneysel sonuçlar}

$\mathrm{Bu}$ çalışmada deney platformu olarak Şekil 2 de fotoğrafı verilen ters sarkaç mekanizması kullanılmıştır. Sarkacın üzerine tutturulduğu araba, 1.8m hareket mesafesi bulunan bir doğrusal kızak üzerinde bağlanmış kayış kasnak mekanizması ile hareket etmektedir. Kayış kasnak mekanizmasının hareketi Maxon marka RE50 model, 
200Watt, 24V luk DC motor ile sağlanmaktadır. Sarkaç araba üzerine tutturulmuş bir şaft ile serbestçe dönmektedir.

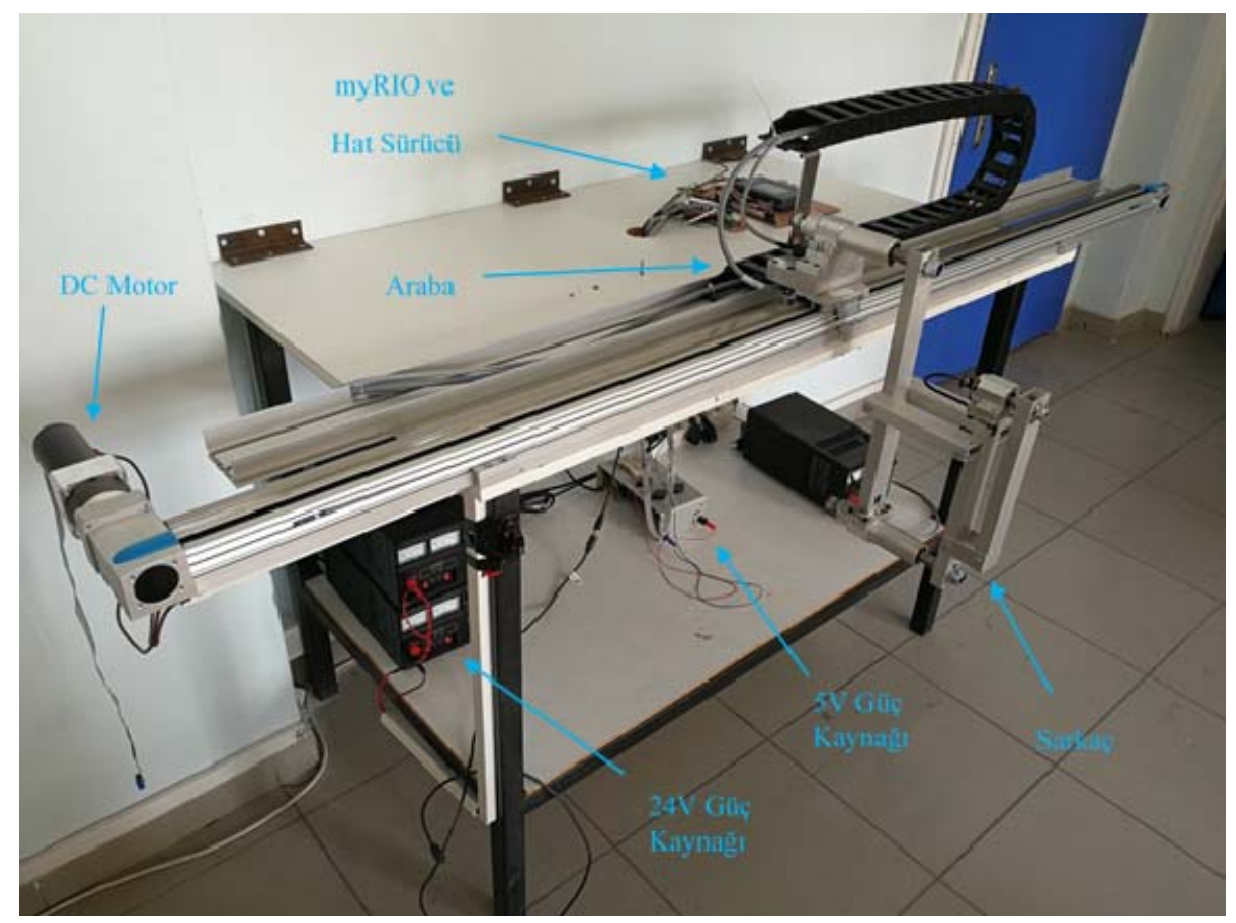

Şekil 2. Deney düzeneği.

Arabanın konumu $0.025 \mathrm{~mm}$ çözünürlüklü doğrusal artımlı enkoder ile ve sarkacın açısı ise 3.142e-4 (0.018 derece) çözünürlüklü dönel artımlı enkoder ile ölçülmektedir. Motor sürücü olarak Pololu marka 24v23 CS model 24V, 500 Watt lık tam köprü PWM sürücüsü kullanılmıştır. Geliştirilen kontrol sistemlerinin gerçeklenebilmesi ve deneysel düzenek üzerinde test edilebilmesi için ARM Cortex A9 işlemciye ve Xilinx Zynq 7 FPGA e sahip olan myRIO gömülü sistemi kullanılmıştır. myRIO nun programlanmasinda grafiksel programlama arayüzü olan Labview programı kullanılmıştır. Geliştirilen uyarlamalı kazançlı ayrık yüzeyli kayan kip denetleyici için oluşturulan Labview yazılımının blok şeması Şekil 3'de ve deney esnasında alınan ön panel görüntüsü ise Şekil 4'de verilmiştir.

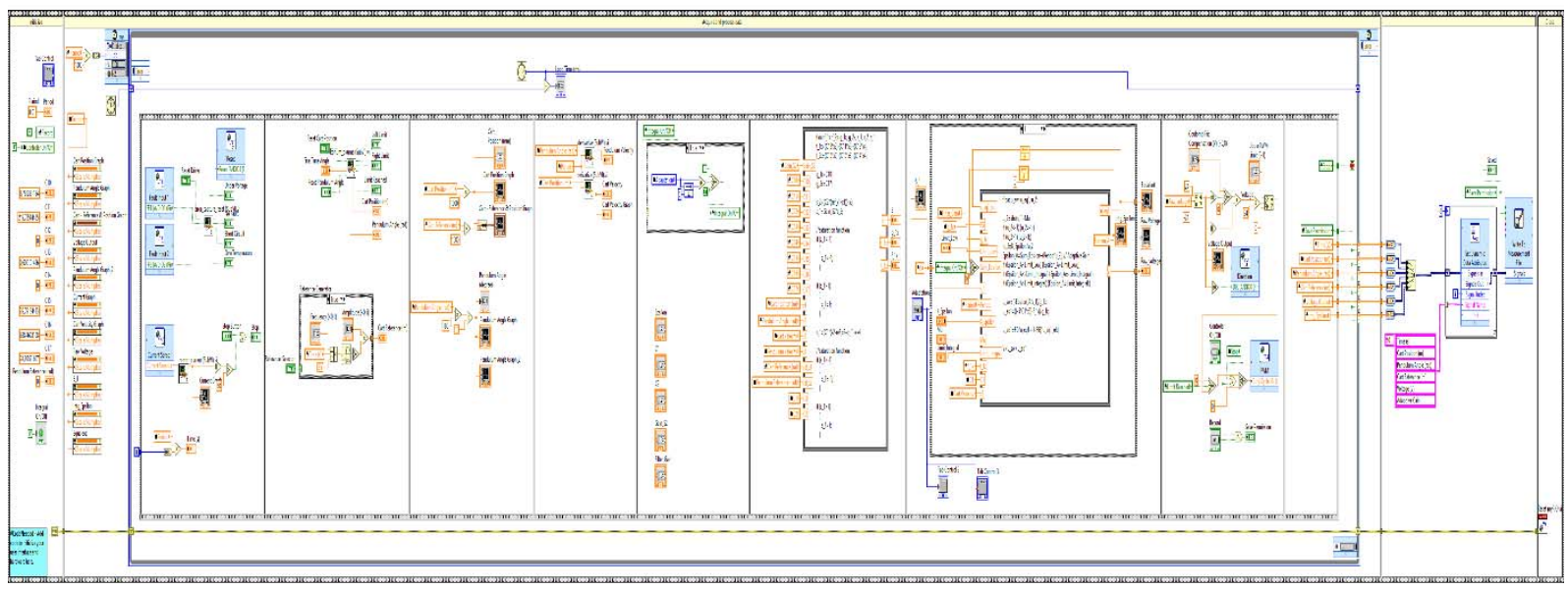

Şekil 3. Labview blok şeması. 


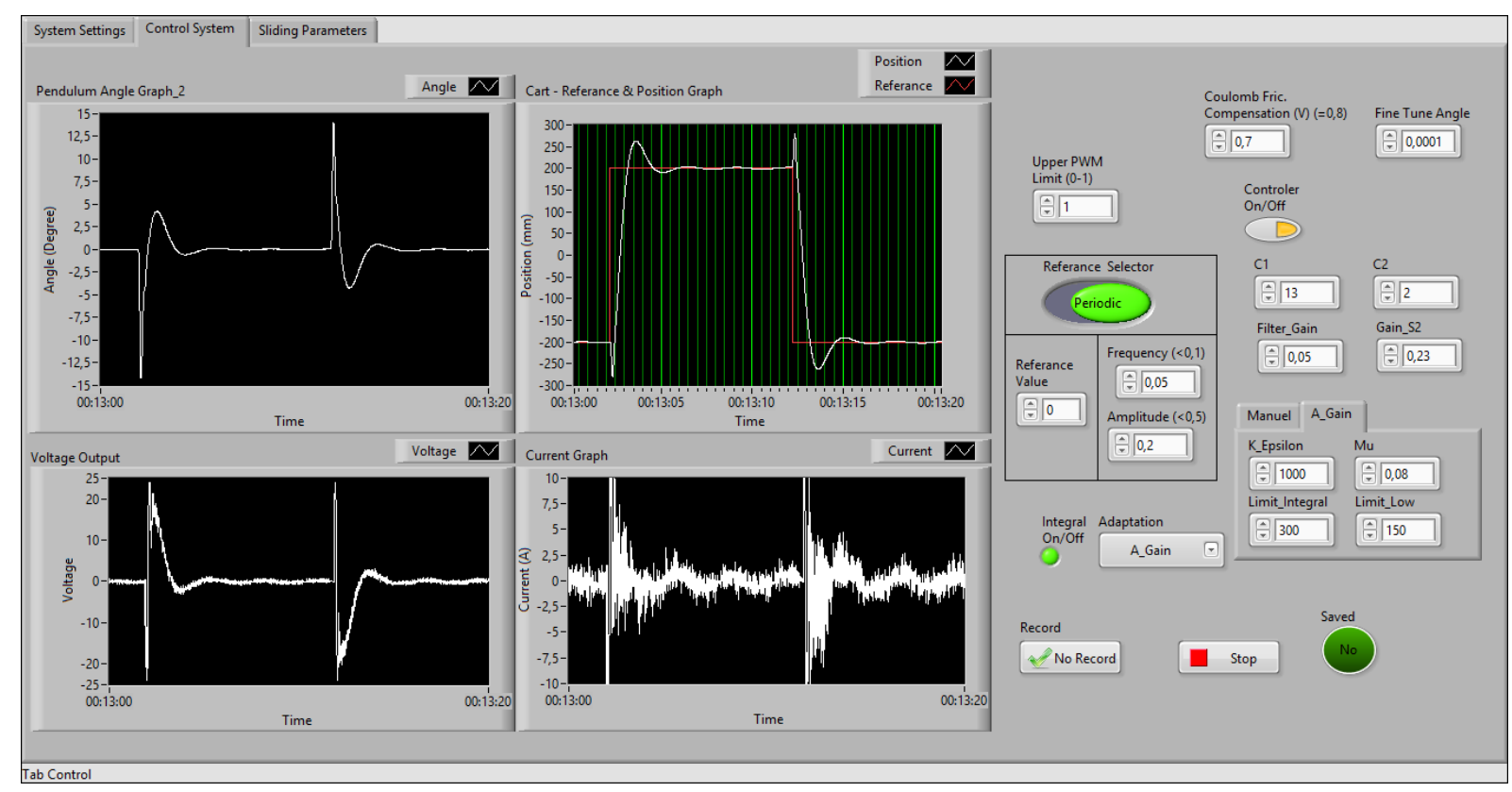

Şekil 4. Labview ön paneli.

Kontrol sisteminin performansının belirlenmesi için yapılan deney ve benzetim testlerinde arabaya uygulanan referans sinyali $+/-0.2 \mathrm{~m}$ genliğe ve 20 sn periyota sahiptir.

Şekil 5'te deneysel düzenek ve benzetim modeli üzerinde arabanın x eksenindeki konum denetimi için uygulanan referans ve elde edilen konum grafikleri görülmektedir. Sarkacı düşürmeden arabayı hareket ettirebilmek için sarkacın araba hareketinin sağlanacağ 1 yöne eğilmesi yani araba hareketinden doğan ters momentin yerçekimi ivmesi ile dengelenmesi gerekir. Bu nedenle referans sinyalin başlangıç anında denetim sistemi, sarkacı arabanın gitmesi istenen yönde eğebilmek için arabayı istenen konuma ters yönde hareket ettirmektedir. Denetim sistemi hareketin devamında eğilen sarkacın düşmesini engellemek için arabayı istenen konuma doğru sürmektedir. Kayan kip denetimde, arabanın ve sarkacın konumları için bağımsız olarak oluşturulan kayma yüzeyleri ve hata bileşenleri Eş. 11-14'te görülmektedir. Araba için oluşturulan $\left(s_{2}\right)$ kayma yüzeyi üzerinde kayma kipine ulaşıldığında hata sıfıra eşit olur.

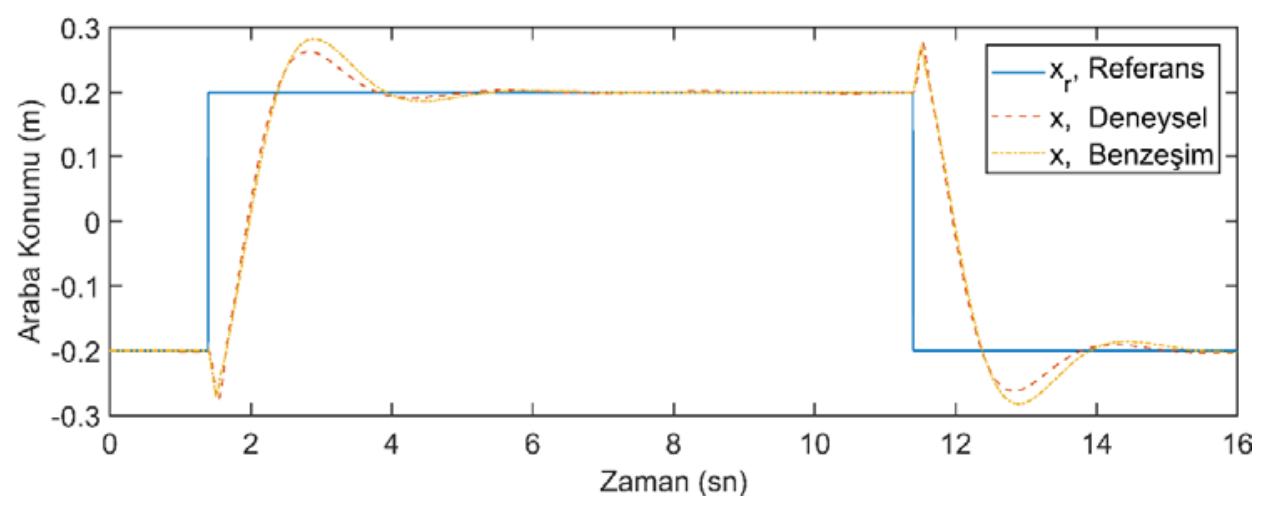

Şekil 5. Araba için deneysel ve benzetim çizgisel konum zaman grafiği. 
Şekil 6'da deneysel düzenek ve benzetim modeli üzerinde arabanın çizgisel konum denetimi yapılırken sarkacın $\mathrm{z}$ eksenindeki dengeleme denetim sisteminin cevabını gösteren açısal konum-zaman grafikleri verilmektedir. Arabanın istenilen konuma hareket ettirilebilmesi için gerçekleşen eğilme hareketi ve sonrasında araba istenilen konuma yaklaştıkça sarkacın denge konumuna geldiği gözlemlenmektedir. Hareket esnasında sarkacın istenmeyen geri dönüşler diğer bir deyişle salınım hareketleri yapmadığ1 görülmektedir. Şekil 5 ve 6'dan gözlemlenen denetim sistemi cevapları geliştirilen uyarlamalı kazançlı kayan kip denetimin başarımını ortaya koymaktadır.

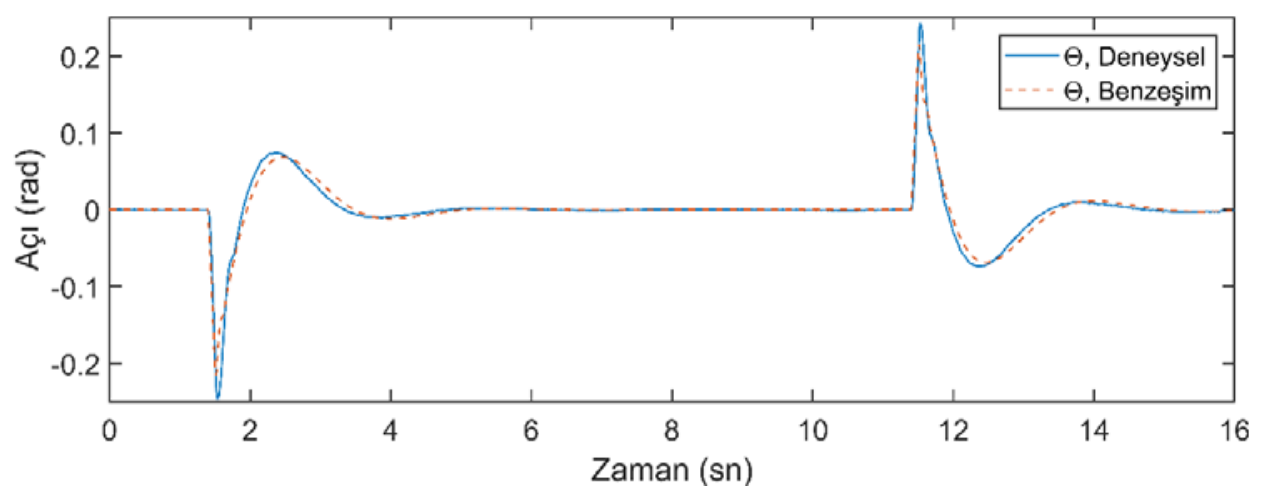

Şekil 6. Sarkaç için deneysel ve benzetim açısal konum zaman grafiği.

Şekil 7'de verilen grafikte anahtarlama fonksiyonunun genliğini belirleyen uyarlamalı kazanç değişimi görülmektedir. Araba konum referansının $\pm 0.2 \mathrm{~m}$ genlikli adım fonksiyonu olarak verildiği durumda, denetim sisteminin kazancı kayma yüzeylerini oluşturan hataları sıfıra götürebilmek için artmaktadır. Kayma kipine ulaşıldığında kazanç sabit kalmakta ve sonrasında mümkün olan en küçük değerine ulaşmaktadır. Böylece çatırdama etkisi ile doğrudan ilişkili olan kazanç sayesinde çatırdama etkisi de en aza indirilmektedir.

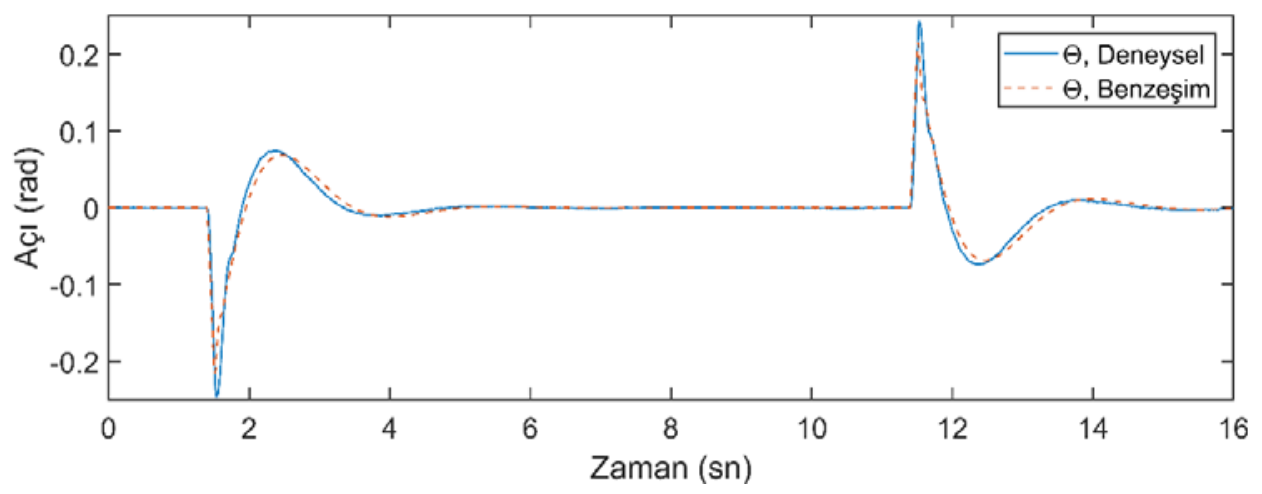

Şekil 7. Uyarlamalı kazanç değişim grafiği.

Şekil 8'de, eksik eyleyicili yani tek motorla iki eksenin denetlendiği sistemde motora uygulanan gerilime ait değişimler görülmektedir. Şekil 8'de verilen açısal konum ve çizgisel konum grafikleri ile uyumlu olarak gerilim değişimi gözlenmektedir. Her iki eksen için referans değerlere ulaşıldığında gerilim değişimi yaklaşık sıfır olmaktadır. 


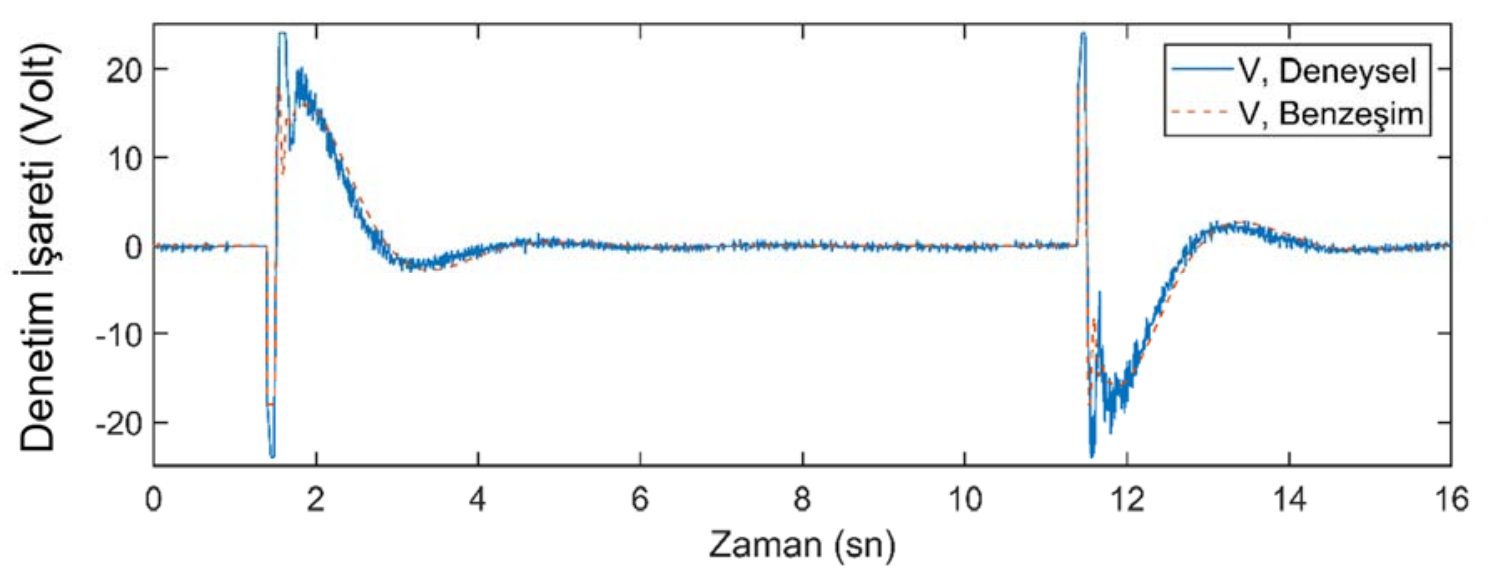

Şekil 8. Sisteme uygulanan gerilimin değişim grafiği.

Şekil 9'da araba ve sarkaç için hata grafikleri verilmiştir.

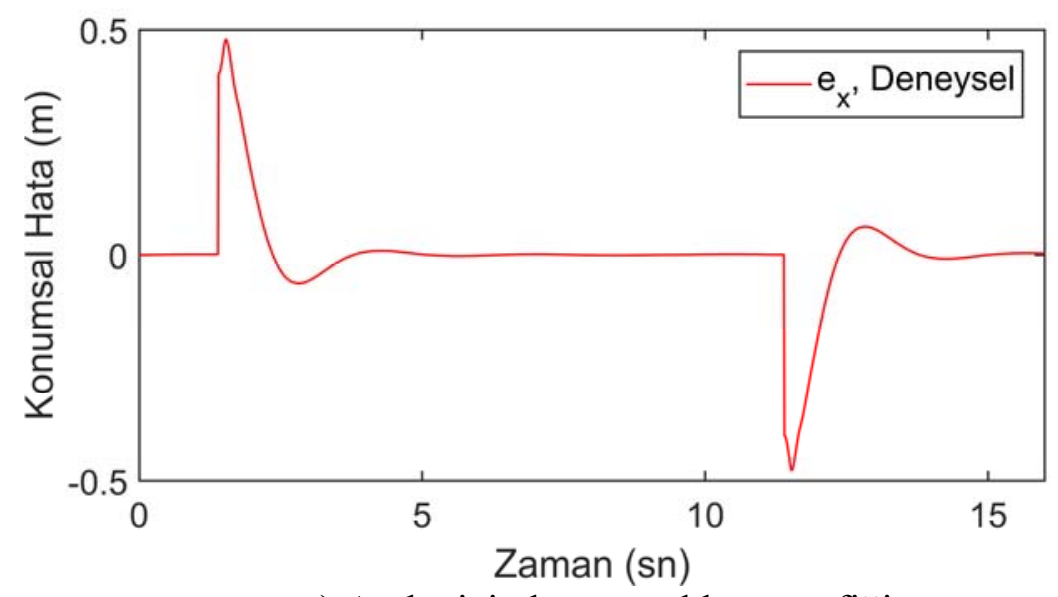

a) Araba için konumsal hata grafiği

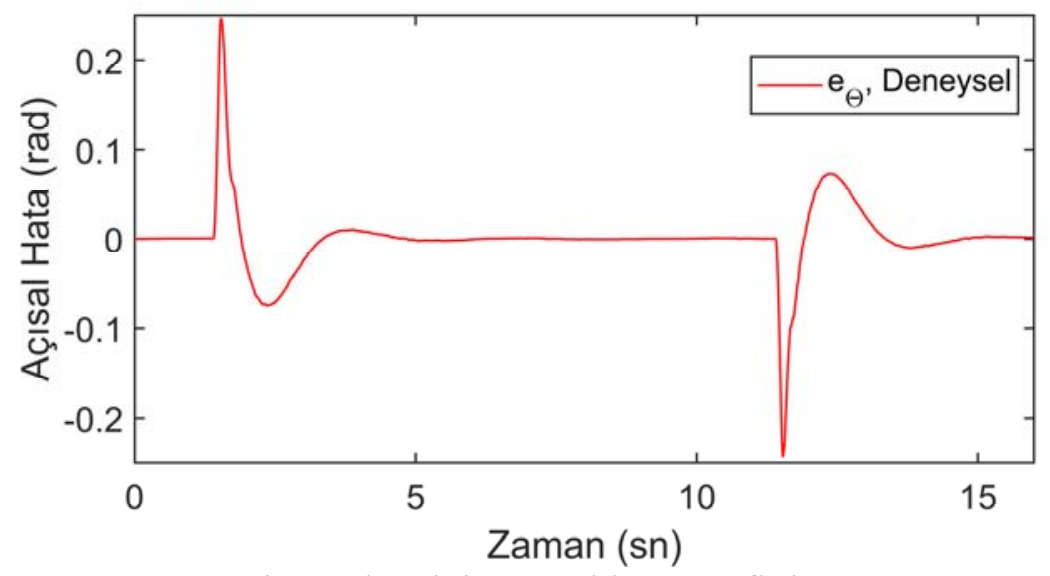

b) Sarkaç için açısal hata grafiği

Şekil 9. Araba ve sarkaç için hata grafikleri

Şekil 5-9'da verilen grafiklerde Labview programı ile yapılan deneylerin ölçümleri myRIO denetim kartı üzerinde bulunan USB belleğe kaydedilmiştir. Daha sonra MATLAB/Simulink programından elde edilen grafik bilgileri ile bir araya getirilmiştir. 


\section{Sonuç}

Uyarmalı kazançlı bağımsız yüzeyli kayan kip yöntemi ile ters sarkacın denetimi deneysel olarak gerçekleştirilmiştir. Deneysel sonuçlarla MATLAB/Simulink programı kullanılarak elde edilen benzetim sonuçları karşılaştırılmıştır. Elde edilen sonuçlardan karşılaştırmalı sonuçlar birbirine oldukça yakın çıkmıştır. Bozucu etkilerin sisteme etki ettiği durumlarda sabit kazançlı kayan kip denetimin çatırdama etkisini arttırdı̆̆ bilinmektedir. Buna göre uyarlamalı kazançlı kayan kip denetimle hem çatırdama etkisi azaltılmış hem de bozucu etkilere karşı daha dayanıklı bir denetim yapısı elde edilmiştir. İlgili sonuçlar denetim sisteminin başarımının yüksek olduğunu doğrulamaktadır.

\section{Kaynaklar}

[1] Mahapatra, C., Chauhan, S. ve Hemakumar, B., Servo control and stabilization of linear inverted pendulum on a cart using LQG, 2018 International Conference on Power Energy, Environment and Intelligent Control (PEEIC), 783-788, India, (2018).

[2] Mobara, M., Karimpour, A., Ahamadian, H. M. ve Pahnabi, A., Modeling control of inverted pendulum based on PWA-fuzzy approach, Second International Congress on Technology, Communication and Knowledge(ICTK 2015), 112-116, Iran, (2015).

[3] Brill, A., Frank, J. A. ve Kapila V., Visual servoing of an inverted pendulum on cart using a mounted smartphone, American Control Conference (ACC), 13231328, Boston, (2016).

[4] Bakarac, P., Klauco, M. ve Fikar, M., Comparison of inverted pendulum stabilization with PID, LQ, and MPC control, Proceeding of the 29th International Conference 2018 Cybernetics\&Informatics (K\&I), 1-6, Slovakia, (2018).

[5] Nath, K. ve Dewan, L., Control of rotary inverted pendulum via adaptive techniques, International Conference on Emerging Trends in Computing and Communication Technologies (ICETCCT),1-6, India, (2017).

[6] Mahaaptra, C. ve Chauhan, S., Tracking control of inverted pendulum on a cart with disturbance using pole placement and LQR, International Conference on Emerging Trends in Computing and Communication Technologies (ICETCCT), 1-6, India, 2017.

[7] Sarkar, T. T. ve Dewan, L., Application of LQR and MRAC for swing up Control of inverted Pendulum, 4th International Conference on Power, Control \& Embedded Systems (ICPCES), 1-6, India, (2017).

[8] Gautam, P., Optimal control of inverted pendulum system using ADALINE artificial neural network with LQR, IEEE International Conference on Recent Advances and Innovations in Engineering (ICRAIE), 1-6, Jaipur, (2016).

[9] Wang, J. ve Kumbasar, T., Big Bang-Big Crunch optimized hierarchical slidingmode control of X-Z inverted pendulum, Simulation Modelling Practice and Theory, 86, 25-35, (2018).

[10] Wanga, Y., Xia, Y., Li, H. ve Zhou, P., A new integral sliding mode design method for nonlinear stochastic systems, Automatica, 90, 304-309, (2018). 
[11] Khan, Q., Akmeliawati, R., Bhatti, A. I. ve Khan, M. A., Robust stabilization of under actuated nonlinear systems: A fast terminal sliding mode approach, ISA Transactions, 66, 241-248, (2017).

[12] Li, P., Yu, X. ve Xiao, B., Adaptive quasi-optimal higher order sliding-mode control without gain overestimation, IEEE Transactions On Industrial Informatics, 14, 9, 3881-3891, (2018).

[13] Baek, S., Baek J. ve Han, S., An adaptive sliding mode control with effective switching gain tuning near the sliding surface, IEEE Access, 7, 155563-15572, (2019).

[14] Shi, S., Li, J. ve Fang, Y., Extended-state-observer-based chattering free sliding mode control for nonlinear systems with mismatched disturbance, IEEE Access, 6, 22952-22957, (2018).

[15] Repecho, V., Biel, D., Lara R. R. ve Vega, P. G.,Fixed-switching frequency interleaved sliding mode eight-phase synchronous buck converter, IEEE Transactions On Power Electronics, 33, 1, 666-688, (2018).

[16] Guo, Y., Ma, B., Chen, L. ve Wu, R., Adaptive sliding mode control for a class of Caputo type fractional-order interval systems with perturbation, IET Control Theory \& Applications, 11, 1, 57-65, (2017).

[17] Van, M., Ge, S. S., ve Ren H., Robust fault-tolerant control for a class of second-order nonlinear systems using an adaptive third-order sliding mode control, IEEE Transactions On Systems, Man, And Cybernetics: Systems, 47, 2, 221-228, (2017).

[18] Baek, J., Jin, M., ve Han S., A new adaptive sliding-mode control scheme for application to robot manipulators, IEEE Transactions On Industrial Electronics, 63, 6, 3628-3637, (2016).

[19] Tiga, A., Ghorbel, B. ve Braiek, B., Performance comparison of backstepping and sliding mode controllers, International Conference on Advanced Systems and Electric Technologies (IC_ASET), 461-466, Tunusia, (2018).

[20] Muhammad, S. ve Idrees, M., Comparative study of hierarchical sliding mode control and decoupled sliding mode control, IEEE Conference on Industrial Electronics and Applications (ICIEA), 818-823, Cambodia, (2017).

[21] Utkin, V. I., Variable Structure systems with Sliding Modes. IEEE Transaction on Automatic Control, 22, 2, 212-222, (1977).

[22] Utkin, V. I. ve Poznyak, A. S., Adaptive sliding mode control with application to super-twist algorithm: Equivalent control method, Automatica, 49, 39-47, (2013).

[23] Plestan, F., Shtessel, Y., Bregeault, V. ve Poznyak, A., Sliding mode control with gain adaptation-Application to an electropneumatic actuator, Control Engineering Practice, 21, 679-688, (2013). 